to secure co-ordination between the scientific departments of the fighting Services and the Ministry of Supply, and the extent of the co-operation between the British and French Governments in these matters. Lord Strabolgi said he did not wish his remarks to be interpreted as hostile to the Government, and he paid tribute to the strength of the recently appointed Advisory Council of Scientific Research and Technical Development. The reply elicited from Lord Chatfield, Minister for the Co-ordination of Defence, was informative and important as indicating the extent to which the knowledge and services of men of science are being utilized.

Lord Chatfield paid a tribute to the value of scientific research to the Services. The existing establishments were in the main created after the War of 1914-18 or during its later years. They now include many of the leading men of science in the country, either in a working or advisory capacity. He referred to eight research laboratories under the Department of Scientific and Industrial Research, and said: "Generally it is perfectly correct to say that the scientific talent of this country is fully mobilized to its fullest advantage and runs into a very large number of scientists, to be numbered rather in thousands than in hundreds." There is no central organization for dealing with inventions, which actually constitute only a small part of the scientific work in progress. Each Service department and the Air Raids Department of the Ministry of Home Security has its own organization for dealing with inventions, and there is constant consultation between these bodies.

Dealing with the exchange of scientific knowledge between the British and French Governments, Lord Chatfield said that co-operation had begun before the outbreak of war, and that there is now "complete exchange of scientific information". Members of the scientific organizations of the two countries are working in each other's establishments. Further efforts are being made, however, to extend the present liaison. Steps are under consideration to safeguard the interest of inventors, and it is likely that machinery similar to that used during the War of 1914-18, namely, a Commission of Awards to Inventors, would be adopted.

\section{Science and War}

Protection of civilian population from attack by deadly weapons that science has created is set forth as one of the paramount duties of science in the present emergency, in the annual report by Dr. Vannevar Bush, president of the Carnegie Institution of Washington, recently issued. The same science which saves life and renders it rich and full, also destroys it and renders it horrible. Is it then possible to remain in a detached atmosphere to cultivate the slowly growing body of pure scientific knowledge, and to labour apart from the intense struggle in which the direct application of science now implies so much for good or ill? As science has produced a weápon, so also can it produce in time a defence against it. Science is dedicated to the advance of knowledge for the benefit of man. Here is a sphere where the benefit might perhaps indeed be immediate, real and satisfying. Can a scientific worker, skilled in a field such that his efforts might readily be directed to the attainment of applications which would afford protection to his fellow-men against such an overwhelming peril, now justify expending his effort for any other and more remote cause ?

Although immediate participation of the men of science in the safeguarding of civilization is urged by Dr. Bush, he gives the warning that we should not become stampeded. "There is still a duty to keep the torch of pure science lit, and this duty is only the greater under stress. All the long struggle of a harsh evolution, the pitting of species against the environment, has produced a being whose primary distinction is conscious cerebration, and whose crowning attribute is his intellectual curiosity concerning his complex environment and a thirst for knowledge transcending the mere struggle for existence. If there is no abiding value in a Beethoven symphony, or a theory of the cosmos, or the tracing of an ancient culture, then the Carnegie Institution of Washington has scant reason for existence. If it is really good that man should look at the stars and should contemplate his great destiny, then it is imperative that in those regions which enjoy the blessings of peace the search for the eternal verities should continue."

\section{Recent Earthquakes}

AFTERSHOCKs of the earthquake of December 26 in Turkey continue to be felt in widely separated areas. The epicentres are by no means confined to the Erzinjan-Erbaa area, thus lending support to the original estimate from Istanbul of a depth of focus of the original earthquake of the order of sixteen miles. On January 17 eight rather violent tremors were felt in the original area and other violent tremors were experienced at Istanbul, Smyrna, Castamouni, and Izmid. A Times report states that at the last-named place an entire hill slid downwards, blocking the road to Kandira. No further casualties are reported from these areas. On January 16 an earthquake occurred at the village of Balcikoy near Nigde, causing two hundred houses to collapse, killing five people and injuring sixteen. The death roll was small because a light foreshock preceded the principal shock, causing people to run out of doors. On January 17 at night, two more violent earthquakes were felt at Nigde, which is in southern Anatolia. These caused four hundred houses to collapse, killing fifty people and injuring a hundred and sixty others. A. Hée of the central seismological bureau, now at ClermontFerrand (France), has taken the readings of fifteen observatories and determined the epicentre of the original shock to have been near latitude $39 \cdot 5^{\circ} \mathrm{N}$., longitude $38 \cdot 2^{\circ}$ E. ; initial time 26 d. $23 \mathrm{~h} .57 \mathrm{~m}$. $23 \mathrm{~s}$. G.M.T.

An earthquake of intensity VII, and approaching intensity VIII on the modified Mercalli scale of 1931, was felt in Palermo at 2.18 p.m. (local time) on January 15. Much damage is reported to have been 